\section{INDICADORES PARA EL MONITOREO Y EVALUACIÓN DE LA GESTIÓN SOCIO- HABITACIONAL EN CIUDADES NO METROPOLITANAS'}

Daniela Mariana Gargantini²

\section{Resumen}

En América Latina los centros no metropolitanos verifican una mayor concentración de situaciones deficitarias a nivel habitacional y urbano que los que no lo son, manifestándose a la vez como los escenarios prioritarios y con mayor flexibilidad para combatirlas.

Estos aspectos han incitado a que los gobiernos locales de estas ciudades resignifiquen sus viejas funciones para lograr mayor eficacia y eficiencia en sus acciones. De esta manera, los municipios se han visto obligados a asumir, a pesar de sus limitaciones, actitudes activas orientadas al desarrollo local.

Para tal objetivo, nuevos requerimientos metodológicos e instrumentales a nivel de gestión local

\section{INDICATORS FOR THE MONITORING AND EVALUATION OF SOCIO- HOUSING MANAGEMENT IN NON-METROPOLITAN CITIES ${ }^{1}$}

Daniela Mariana Gargantini²

\section{Abstract}

In Latin America, non-metropolitan centers present great shortfalls at housing and urban levels than other type of cities, thus becoming the primary and more flexible spaces to tackle such difficulties.

These aspects have made the local governments of these cities to redefine their old functions in order to achieve efficacy and efficiency. In this way, municipalities have been forced to assume, despite their limitations, active developmentoriented attitudes.

To this end, new methodological and instrumental tools at local housing management 
del hábitat son demandados, a fin de incrementar el impacto y la capacidad para actuar eficazmente frente a la problemática socio-habitacional.

El presente artículo intenta definir las principales dimensiones, variables e indicadores a considerar, a la hora de monitorear la gestión local del hábitat en ciudades no metropolitanas desde una perspectiva integral y asociativa del hábitat social. Con ello se busca brindar elementos objetivos para incrementar la capacidad institucional de los gobiernos locales ante la problemática socio-habitacional a la que deben hacer frente.

PALABRAS CLAVE: INDICADORES DE GESTIÓN, POLÍTICAS HABITACIONALES, GOBIERNOS LOCALES.

Fecha de recepción: 09.03.12

Fecha de aceptación: 31.01.13

1 El presente artículo se estructura en base al aporte de las reflexiones y resultados obtenidos en tesis de posgrado del autor (Gargantini, 2005 y 2010).

2 Argentina. Arquitecta. Magíster en Hábitat y Vivienda, con especialidad en Promoción y Gestión del Desarrollo Local (España). Doctora en Arquitectura por la Universidad Nacional de Rosario (Argentina). Investigadora asistente del Consejo Nacional de Investigaciones Científicas y Técnicas (CONICET-Argentina) y académica de la Facultad de Arquitectura de la Universidad Católica de Córdoba. Miembro del equipo técnico del Centro Experimental de la Vivienda Económica. Email: dgargantini@ceve. org.ar level are required to increase the impact and capacity to effectively address socio-housing problems.

This paper makes an attempt to define the main dimensions, variables and indicators when monitoring local housing management in nonmetropolitan cities from an integral and associative perspective of social housing. The aim of this research is to provide objective elements aimed at increasing the institutional capacity of local governments when facing socio-housing problems.

\section{KEYWORDS: INDICATORS, MANAGEMENT, HOUSING} POLICIES, LOCAL GOVERNMENTS.

1 This paper is based on the contribution of the reflections and results derived from the postgraduate thesis of the author (Gargantini, 2005 and 2010.)

2 Argentina. Architect, MA in Habitat and Housing, with specialty in Promotion and Management of Local Development (Spain.) Ph.D. in Architecture, Rosario National University (Argentina.) Assistant researcher, National Council of Scientific and Technical Investigation (CONICET-Argentina.) Academic, Faculty of Architecture, Catholic University of Cordoba. Member of the technical team for the Experimental Center of Low-Cost Housing. Email: dgargantini@ceve.org.ar 


\section{Introducción}

Desde las últimas décadas del siglo XX las ciudades han adquirido un nuevo protagonismo, con una tendencia cada vez mayor a que sean centro de decisiones de políticas innovadoras, artífices de relaciones comerciales punto a punto sin intermediación de jurisdicciones provinciales o nacionales. Esto genera una tensión constante entre los procesos de globalización y de localización, que actúan como fuerzas influyentes en la forma que adopta el desarrollo en cada sociedad, en torno a la búsqueda de identificar proyectos de futuro en los ámbitos más cercanos ${ }^{3}$.

Frente al proceso de localización, el presente artículo propone la identificación, descripción y justificación de indicadores que faciliten el monitoreo y la evaluación de la gestión local del hábitat en ciudades no metropolitanas, desde una perspectiva integral y asociativa del hábitat social.

Este recorte temático se sustenta en la necesidad de contar con herramientas que permitan dar cuenta de las condiciones que poseen los municipios para hacerse cargo de las nuevas funciones y desafíos que plantea la problemática socio-habitacional existente, así como determinar el nivel de adecuación que sus modos de gestión poseen en relación a una concepción de vivienda que supere la mera condición física, favoreciendo estrategias integrales y que incrementen la participación y la articulación actoral, tal como los desafíos actuales plantean.

Estos desafíos parecen indicar que el ámbito local se configura como el más favorable para propiciar estrategias superadoras, y que la vivienda constituye un punto de partida viable para institucionalizar cambios en los modelos de gestión de las políticas sociales hoy vigentes (entre ellas la habitacional). Para ello, nuevos requerimientos metodológicos y operacionales innovadores a nivel de gestión local del hábitat son necesarios.

Bajo este marco, el presente artículo intenta definir y descomponer analíticamente las principales dimensiones, variables e indicadores a considerar en la elaboración de una matriz teórico-instrumental, aplicable a la realidad de los municipios de ciudades no metropolitanas, necesarios para monitorear la gestión local del hábitat y ponderar el grado de implementación local de procesos integrales y asociativos de hábitat social destinados a sectores de menores recursos. Con ello se busca brindar elementos objetivos para encauzar líneas políticas y decisiones gubernamentales en curso, o bien diseñar futuras acciones, incrementando la capacidad institucional de los gobiernos locales ante la problemática socio-habitacional a la que deben hacer frente.

3 García Delgado, 1997. 


\section{Los desafíos de las ciudades no metropolitanas ante la situación socio-habitacional actual}

Los análisis estadísticos provistos por la Comisión Económica para América Latina y el Caribe $(\text { CEPAL })^{4}$, manifiestan que en 2010 el 31,4\% de la población de la región vive en condiciones de pobreza (177 millones de personas) y un 12,3\% de la población (70 millones de personas) vive en la pobreza extrema o indigencia.

Este asunto tiende a complejizarse cuando se considera la creciente tendencia a la urbanización en América Latina y el Caribe (78\% de la población es urbana $)^{5}$. Estas características le otorgan un sesgo eminentemente urbano a la pobreza regional, con tendencia a acompañar el preeminente crecimiento poblacional que se prevé en el futuro para las ciudades no metropolitanas.

Naciones Unidas. 2012.

5 United Nations, 2002.

72

revista invi № 77 / Mayo 2013 / Volumen № 28: 69-109
En materia habitacional, las privaciones en lo que respecta a la calidad de la vivienda y el acceso a ciertos servicios básicos suelen ser la cara más visible de la pobreza de los hogares. Si bien estudios efectuados en los últimos años desde una percepción más integral de la pobreza (que supera el mero análisis de carencias materiales medidas en ingresos o gastos de los hogares) han señalado que pobreza urbana y precariedad habitacional no siempre coinciden en las ciudades latinoamericanas $^{6}$, de manera general no menos del $60 \%$ de los hogares que posee alguna privación habitacional o de servicios son pobres, y en algunos casos la cifra llega a ser considerablemente más alta. Y en base a datos provistos por $\mathrm{CEPAL}^{7}$ los porcentajes de incidencia de la pobreza en los hogares producto de las características de las viviendas, si bien mantienen diferencias considerables entre países, resultan elevados para la región en términos generales ${ }^{8}$.

Unido a ello se verifica una paulatina concentración de todos los tipos de precariedades analizados en los centros no metropolitanos, manifestándose como los escenarios prioritarios y con mayor

Mac Donald, 2004.

Naciones Unidas, 2005.

"Si bien se han intentado incluir parámetros más complejos (como la localización riesgosa de las viviendas y el escaso reconocimiento en las políticas públicas), los aspectos para caracterizar la precariedad del hábitat urbano latinoamericano son cuatro condiciones deficitarias básicas: condición de tenencia de la vivienda, acceso al agua segura, acceso al saneamiento y calidad de la vivienda" (Mac Donald, 2004). 
flexibilidad para combatir la precariedad y la pobreza socio-habitacionales?.

"El panorama regional de los asentamientos latinoamericanos se caracteriza por la presencia de múltiples expresiones de pobreza urbana, lo cual exige modalidades diferenciadas de gestión de nuestras ciudades para reducirla"10. La fuerte tendencia a la urbanización, el paulatino crecimiento de las ciudades en los centros medianos y menores, la consolidación material de la informalidad de las metrópolis frente a la formalización de la precariedad material del resto urbano, la relevancia de la exclusión de los servicios básicos que sufren los pobres urbanos, y la inseguridad en la tenencia resultan fuertes desafíos y tareas pendientes en el diseño y ejecución de programas de combate contra la precariedad habitacional.

Junto a esta situación deficitaria y a la incapacidad que las diferentes políticas habitacionales implementadas en la región han manifestado históricamente frente a la misma, los cambios socio-económicos y políticos acontecidos en los últimos años han planteado la renovación del papel específico de las ciudades, incrementando el protagonismo de los ámbitos locales y propiciando modificaciones en sus modos de gestión.

\footnotetext{
9 Mac Donald, 2004.
}

10 Ibíd.
Estos aspectos han incitado a que los gobiernos locales resignifiquen sus viejas funciones, se ocupen de nuevos temas y desarrollen nuevas tareas por sobre sus competencias habituales, a fin de lograr mayor eficacia y eficiencia en sus acciones. De esta forma, los municipios se han visto obligados a renunciar a su carácter instrumental y despolitizante, asumiendo, a pesar de sus limitaciones presupuestarias y técnicas, actitudes activas orientadas al desarrollo local a nivel económico, social, cultural y político.

En materia social, esta resignificación parece suponer el mantenimiento de ciertos rasgos de bienestarismo racionalizado, junto al paso de una planificación tecnocrática a una estratégica; de la asistencia social a la promoción social, y de la administración burocrática a una administración gerencial y por proyectos.

Paralelamente, en el campo de las políticas habitacionales, existe un amplio consenso a nivel teórico en torno a la noción de hábitat por sobre la visión mercantil o académica tradicional que concebía la vivienda como objeto o producto aislado. Esta concepción abarcativa del hábitat ha implicado el avance hacia estrategias más integrales y multidimensionales de atención a la pobreza, intentando 
superar las acciones sectoriales y los programas asistenciales de reducción de la pobreza, favoreciendo la integración social y urbana de los sectores de menores recursos, bajo modelos de gestión integrales y multiactorales. Sin embargo, a pesar de los cambios de contexto explicitados y del gran avance teórico-conceptual que se ha desarrollado en torno al hábitat, tanto a nivel político como técnico, la mayoría de los procesos de gestión destinados a la resolución de la problemática socio-habitacional a nivel local se desarrollan bajo modelos de gestión tradicionales y se concentran en la vivienda como producto físico, sin consideración de la estructura socio-económica, institucional y urbana en la que se insertan ${ }^{11}$.

Unido a ello, en los últimos años se evidencia una tendencia de re-centralización de acciones habitacionales en manos de los estados nacionales, quien con disponibilidad de recursos asignados, actúa a nivel municipal, sin que las propuestas terminen de ajustarse a los requerimientos locales. Son escasas las iniciativas de escala que propician desde el ámbito local estructuras de abordaje integrales, integradoras, participativas y asociativas, asumiendo las condicionantes que el contexto actual y particular de los sectores de menores recursos, impone.

Para tal fin, nuevos requerimientos metodológicos e instrumentales a nivel de gestión local del hábitat

11 Gargantini, 2005.

74 revista invi No 77 / Mayo 2013 / Volumen N² 28: 69-109 son demandados, con el propósito de incrementar el impacto y la capacidad para actuar eficazmente frente a la problemática socio-habitacional que se padece.

\section{Los indicadores y su uso}

Un indicador es una información construida con base en datos existentes sobre alguna realidad que puede ser medida cuantitativamente. Su papel es hacer evidente algún rasgo de esa realidad, como resultado de la relación entre dos o más datos, que permiten cuantificar una situación determinada ${ }^{12}$. Todo indicador muestra o indica así el estado particular de una variable, dando una visión sintética y aportando conocimiento sustantivo.

Por su parte, los indicadores de gestión miden el esfuerzo, compromiso, eficiencia, desempeño o dedicación de una organización para alcanzar metas o resolver problemas vinculados al desarrollo de sus funciones sustantivas.

Para el caso particular de intentar ponderar la gestión local del hábitat, los indicadores a seleccionar deben dar cuenta del conjunto de procesos que el gobierno local desarrolla, a fin de articular, usar, coordinar, organizar, asignar recursos que permiten producir, hacer funcionar y mantener satisfechas las necesidades socio-habitacionales de la

12 Pírez, 2000. 
ciudad, en este caso particular con especial énfasis en los sectores de menores recursos.

La identificación y cuantificación de las diferencias en los valores señalan, a quienes tomen decisiones en el municipio, hacia dónde deberían apuntar sus políticas para lograr sus objetivos (en este caso, avanzar hacia procesos más integrales y asociativos de hábitat social destinados a sectores de menores recursos), porque esos conocimientos resultan del uso de datos sobre la realidad de la población, del gobierno municipal, o de los programas o proyectos considerados. Debe, entonces, aceptarse que los indicadores aportan conocimiento para el desarrollo de las acciones municipales, por medio de su contribución a los momentos del diagnóstico, del monitoreo o seguimiento y de la evaluación de las políticas, lo que permitirá su revisión en caso necesario.

Los indicadores también son de gran utilidad para los tomadores de decisiones de los organismos gubernamentales de nivel federal y provincial que tienen que desarrollar políticas que de una u otra forma afectan a las realidades locales.

La elaboración de indicadores se suma, así, a la amplia tarea de ofrecer herramientas para la gestión municipal.

Sus usuarios potenciales son los ciudadanos y la población local, las organizaciones gubernamentales y los actores económicos de diferentes niveles, así como los académicos e investigadores y todo actor social que precise contar con referencias empíricas relevantes para evaluar las situaciones locales y/o elaborar propuestas con relación a ellas.

La utilidad de los indicadores de monitoreo y evaluación de la gestión del hábitat desde el ámbito local que en este artículo se describen, resulta de la evidente necesidad de que toda decisión pública pueda sustentarse en informaciones rigurosas, así como en la urgencia de avanzar hacia procesos integrales y asociativos superadores. Estos indicadores permiten tener una idea de la envergadura de los problemas y del alcance de los recursos con que se cuenta; y facilitan, también, percibir en qué medida una política aplicada produce o puede producir los efectos deseados.

\section{Indicadores de gestión socio- habitacional}

A lo largo de esta ponencia se ha sostenido que las políticas habitacionales desarrolladas en la región durante las últimas décadas han resultado insatisfactorias, y que esto se debe -al menos en gran medida- a la persistencia de modelos de gestión tradicionales que se concentran en la vivienda como producto físico y no terminan de reconocer las implicancias que supone avanzar hacia políticas integrales, donde los condicionantes políticos, el nivel de capacidad institucional instalada, el grado 
de integralidad e integración propuestos, y el nivel de participación y articulación actoral promovidos, resultan variables determinantes y factores condicionantes del impacto, la sustentabilidad de las acciones y la capacidad para actuar eficazmente frente a las problemáticas existentes ${ }^{13}$.

Los indicadores que aquí se muestran se apoyan en una visión integral del desarrollo, y parten de considerar la complejidad y la multidimensionalidad de las problemáticas sociales, tal como resulta la habitacional.

Conciben a la gestión urbana o de la ciudad como "el conjunto de procesos dirigidos a articular, usar, coordinar, organizar, asignar recursos que permiten producir, hacer funcionar y mantener la ciudad y brindar a las actividades económicas y a la población los satisfactores de sus necesidades, tanto bienes de consumo individual como colectivo"14; y al espacio local como ámbito propicio y viable para la implementación de políticas más integrales y abarcativas que contemplen no solo los componentes físicos del hábitat, sino también sociales, institucionales y de contexto.

Desde este punto de vista, "la gestión urbana vincula tres tipos de procesos que configuran la ciudad: los orientados por la búsqueda de ganancia, los comunitarios y los estatales, dándose dicha gestión

13 Para más detalles sobre estos condicionantes, ver Gargantini, 2005 y 2010.

14 Herzer y Pírez, 1999. revista invi Nº 77 / Mayo 2013 / Volumen N² 28: 69-109 en torno a la articulación entre mercado, estado y procesos de reproducción de la población. En este proceso articulador el gobierno local, al relacionarse con los diversos actores presentes, modela un proyecto de ciudad que se traduce en los lineamientos de su gestión"15. Es en torno a estos modelos de gestión de los gobiernos locales en materia socio-habitacional que se centra el presente trabajo.

La expresión modelo de gestión, de acuerdo al marco conceptual seleccionado, define la "estructura integral de abordaje al problema que se intenta resolver: conceptual, institucional y política, con sus definiciones de actores, roles, interrelaciones, fuentes y circuitos de flujo de recursos. (...) La expresión estructurada de un modelo de gestión lo constituye el plan u operatoria, que son lineamientos estructurados como un conjunto de directivas y normas acerca de la modalidad a la que deben responder las diferentes operaciones o proyectos, concebidos como el conjunto de acciones que se llevan a cabo frente a cada caso concreto. El modelo es la guía o instructivo para el diseño de la planificación de las diferentes operaciones posibles: no especifica actores concretos, ni medidas definidas en el tiempo, ni objetivos específicos, etc., que corresponderían a un solo caso en particular, sino secuencias-tipo, actores-tipo, metas-tipo,

15 Herzer, 1999. 
escalas de duración, escalas de presupuesto, a los que deberían responder las operaciones o proyectos concretos, y que le aseguren que la ejecución de los mismos va a responder a los propósitos y a la concepción de la forma de actuar que se posee"16.

Desde este marco, el presente artículo explicita un conjunto de indicadores interrelacionados, comprensibles y relevantes, aplicable a la realidad de los municipios (particularmente los de ciudades no metropolitanas), que permitan monitorear la gestión local del hábitat y ponderar el grado de implementación local de procesos integrales y asociativos de hábitat social destinados a sectores de menores recursos, con el fin de brindar elementos objetivos para encauzar líneas políticas y decisiones gubernamentales en curso, o bien diseñar futuras acciones. Con ello se busca contribuir a mejorar la capacidad municipal para el manejo de esta problemática, ofreciendo herramientas operativas de gestión que permitan alertar sobre posibles problemas, corregir desviaciones, identificar tendencias y orientar los planes y decisiones, consolidando, optimizando y potenciando modos superiores a los actuales.

Cuando se hace referencia a un sistema de indicadores, dichos conceptos remiten "al de agregación o ensamble de objetos unidos por alguna forma metódica de interacción o interdependencia, sobre

16 Pelli, 2000. la base de la interconexión. Un sistema es, entonces, un conjunto de elementos que interactúan entre sí en forma metódica, y alude a una forma de vinculación entre elementos (indicadores) y a un contenido íntimamente relacionado (información estadística). La vinculación entre las partes está dada por la búsqueda de un mismo objetivo. En el caso de un sistema de indicadores municipales, ese objetivo es satisfacer la necesidad de información para el conocimiento y la gestión de los gobiernos locales"17.

Como se ha mencionado, la utilidad de los indicadores como instrumentos de conocimiento deriva de las comparaciones que pueden realizarse con ellos.

En función del recorte temático y para el universo que compete a este trabajo, el sistema de indicadores seleccionados y que aquí se describen permite que estas comparaciones puedan realizarse a partir de la carga individualizada de programas o proyectos:

- A nivel de programas/proyectos: esto es, entre diferentes programas o proyectos socio-habitacionales puntuales y específicos, ejecutados, en curso o por ejecutarse, para conocer si los mismos colaboran en la gestión socio-habitacional local, y en qué sentido lo hacen o podrían hacerlo.

17 Subsecretaría de Asuntos Municipales, 2000. 
- A nivel de gestión local: es decir, entre el conjunto de programas o proyectos socio-habitacionales desarrollados por un mismo municipio, ejecutados, en curso o por ejecutarse, correspondientes a iguales o distintos momentos de tiempo, para conocer si la situación identificada ha cambiado y en qué sentido lo ha hecho o podría hacerlo.

- A nivel intermunicipal: sobre la base de un mapeo de una zona o región, para identificar si la situación evaluada (gestión local del hábitat) es igual o diferente (en más o en menos grado) a la del resto de los municipios y, en consecuencia, preguntarse e intentar explicar el por qué de esas diferencias, capitalizar aciertos y corregir desviaciones.

- A nivel inter-temporal: esto es, entre diferentes períodos temporales, para identificar cómo ha evolucionado (en más o en menos grado) la situación evaluada (gestión local del hábitat), y preguntarse e intentar explicar el por qué dicha evolución.

Todo esto, con formato de autoevaluación interna o como insumo para auditorías externas.

La selección, descripción y justificación de indicadores de gestión socio-habitacional en ciudades no metropolitanas, se estructura a partir de dos niveles de análisis:
- A nivel de caracterización inicial del municipio.

- A nivel de análisis de programas o proyectos habitacionales, considerados principales en la implementación local de procesos integrales y asociativos de hábitat social destinados a los sectores de menores recursos, de acuerdo al marco teórico y a los referentes empíricos detectados en investigaciones anteriores ${ }^{18}$.

A su vez, a nivel de análisis de programas o proyectos habitacionales resulta necesario reconocer:

- Dimensiones de proceso: dan cuenta del proceso general de gestión.

- Dimensiones de resultados: dan cuenta de los resultados alcanzados tras los procesos promovidos.

A partir de ellas y de su conceptualización, a continuación se descompone analíticamente cada dimensión en variables e indicadores.

Los mismos intentan generar puntos de comparación metodológicamente homogéneos, de relativa facilidad de construcción y comunicación, cuantificables a partir de información censal y de los datos generados y aportados por los municipios en sus registros e informes de programas y proyectos socio-habitacionales.

De la misma manera, "alertan sobre posibles problemas, identifican tendencias, facilitan la

18 Gargantini, 2005 y 2010. 


\section{TABLA 1: SISTEMA DE INDICADORES DE GESTIÓN SOCIO-HABITACIONAL LOCAL.}

\begin{tabular}{|c|c|c|}
\hline Dimensiones de proceso & Variables & Indicadores \\
\hline $\begin{array}{l}\text { Estructura conceptual de } \\
\text { abordaje del problema }\end{array}$ & Objetivos y metas & $\begin{array}{l}\text { - Tipo de objetivos generales del programa o proyecto } \\
\text { - Tipo de objetivos específicos del programa o proyecto } \\
\text { - Tipo de metas del programa o proyecto }\end{array}$ \\
\hline Desarrollo temporal & Etapas & - Etapas verificadas en el desarrollo del programa o proyecto \\
\hline \multirow{4}{*}{$\begin{array}{l}\text { Integralidad de las } \\
\text { acciones }\end{array}$} & $\begin{array}{l}\text { Necesidades } \\
\text { satisfechas }\end{array}$ & $\begin{array}{l}\text { - Necesidades humanas que se intentan satisfacer con el pro- } \\
\text { grama o proyecto }\end{array}$ \\
\hline & Objetivos y metas & $\begin{array}{l}\text { - Existencia de otros objetivos en el programa o proyecto que se } \\
\text { suman al de vivienda } \\
\text { - Existencia de otras metas del programa o proyecto que se su- } \\
\text { man al de vivienda }\end{array}$ \\
\hline & $\begin{array}{l}\text { Proyectos } \\
\text { complementarios }\end{array}$ & $\begin{array}{l}\text { - Existencia de otros proyectos complementarios al habitacio- } \\
\text { nal vinculados con el proyecto }\end{array}$ \\
\hline & $\begin{array}{l}\text { Capacidad de gestión } \\
\text { integral instalada en el } \\
\text { municipio }\end{array}$ & $\begin{array}{l}\text { - Áreas o reparticiones vinculadas o afectadas al programa } 0 \\
\text { proyecto } \\
\text { - Formalización de la articulación entre áreas y de procedimien- } \\
\text { tos compartidos en torno al programa o proyecto } \\
\text { - Disciplinas involucradas durante todo el proceso del programa } \\
\text { o proyecto }\end{array}$ \\
\hline $\begin{array}{l}\text { Participación y } \\
\text { articulación de actores }\end{array}$ & Actores involucrados & - Actores sociales involucrados en el programa o proyecto \\
\hline $\begin{array}{l}\text { Participación y } \\
\text { articulación de actores }\end{array}$ & $\begin{array}{l}\text { Espacios de } \\
\text { articulación }\end{array}$ & $\begin{array}{l}\text { - Tipo de articulación entre los actores sociales } \\
\text { - Espacios de involucramiento y asociación generados/ capitali- } \\
\text { zados/ reforzados en el programa o proyecto } \\
\text { - Grado de institucionalización del/los espacio(s) de involucra- } \\
\text { miento y articulación actoral } \\
\text { - Participación de las familias beneficiarias en las diferentes } \\
\text { etapas del programa o proyecto }\end{array}$ \\
\hline
\end{tabular}




\begin{tabular}{|c|c|c|}
\hline Dimensiones de proceso & Variables & Indicadores \\
\hline \multirow{3}{*}{$\begin{array}{l}\text { Capacidad institucional } \\
\text { instalada }\end{array}$} & Técnica & $\begin{array}{l}\text { - Nivel de especialización de los técnicos involucrados en el } \\
\text { programa o proyecto }\end{array}$ \\
\hline & Administrativa & $\begin{array}{l}\text { - Dedicación horaria de los técnicos involucrados } \\
\text { - } \text { - Orrmalización de la designación de los técnicos involucrados } \\
\text { - Existencia de procedimientos formalizados que garanticen el } \\
\text { registro de todas las operaciones (administrativas, económi- } \\
\text { cas, sociales) del programa o proyecto }\end{array}$ \\
\hline & De evaluación & $\begin{array}{l}\text { - Existencia de instancias formales de evaluación y retroalimen- } \\
\text { tación del programa o proyecto }\end{array}$ \\
\hline \multirow[b]{2}{*}{$\begin{array}{l}\text { Condicionamiento } \\
\text { político }\end{array}$} & $\begin{array}{l}\text { Correlación y } \\
\text { coherencia con } \\
\text { los lineamientos } \\
\text { político-programáticos }\end{array}$ & $\begin{array}{l}\text { - Nivel de correlación y coherencia del mismo con los linea- } \\
\text { mientos político-programáticos provistos por dichas políticas }\end{array}$ \\
\hline & $\begin{array}{l}\text { Marco normativo- } \\
\text { organizacional }\end{array}$ & $\begin{array}{l}\text { - Conformación de equipos ad-hoc de trabajo interdisciplinario } \\
\text { e inter-áreas dedicados al hábitat social como problemática } \\
\text { específica } \\
\text { - Grado de formalización de equipos ad-hoc de trabajo interdis- } \\
\text { ciplinario e inter-áreas dedicados al hábitat social como pro- } \\
\text { blemática específica } \\
\text { - Diseño e incorporación de instrumentos legales ad-hoc o fle- } \\
\text { xibilizaciones en los habituales que favorezcan la gestión aso- } \\
\text { ciada e integral del proyecto }\end{array}$ \\
\hline
\end{tabular}

Fuente: elaboración propia, 2011. 
TABLA 2: SISTEMA DE INDICADORES DE GESTIÓN SOCIO-HABITACIONAL LOCAL.

\begin{tabular}{|c|c|c|}
\hline Dimensiones de resultado & Variables & Indicadores \\
\hline \multirow{5}{*}{$\begin{array}{l}\text { Nivel socio-económico } \\
\text { de los beneficiarios del } \\
\text { proyecto }\end{array}$} & Ubicación inicial & - Zona de ocupación inicial de la comunidad \\
\hline & Nivel educacional & - Nivel educativo alcanzado por la población objetivo \\
\hline & Nivel económico & $\begin{array}{l}\text { - } \quad \text { Ingreso familiar respecto LP } \\
\text { - } \quad \text { Porcentaje de hogares con NBI } \\
\text { - } \quad \text { Categorías ocupacionales más frecuentes y nivel de estabili- } \\
\text { dad laboral de los jefes de familia }\end{array}$ \\
\hline & Situación laboral & $\begin{array}{l}\text { - Tasa de desocupación } \\
\text { - Tipo de oficios más frecuentes } \\
\text { - } \quad \text { Existencia y tipo de MYPES } \\
\end{array}$ \\
\hline & Situación habitacional & $\begin{array}{l}\text { - } \mathrm{N}^{\circ} \text { total de viviendas existentes en asentamiento original } \\
\text { - } \% \text { de hogares en viviendas deficitarias por precariedad o \% de } \\
\text { hogares en viviendas con clasificación CALMAT III o IV } \\
\text { - } \% \text { de hogares particulares con hacinamiento personal } \\
\text { - } \% \text { de hogares particulares con hacinamiento familiar o de } \\
\text { hogares } \\
\text { - } \% \text { de hogares con cobertura de infraestructura urbana } \\
\text { - Existencia de servicios urbanos }\end{array}$ \\
\hline \multirow[t]{2}{*}{ Implantación territorial } & Escala de intervención & $\begin{array}{l}\text { - Escala de la intervención urbano-habitacional del programa o } \\
\text { proyecto }\end{array}$ \\
\hline & Tipo de radicación & - Ubicación final de la comunidad o tipo de radicación promovida \\
\hline \multirow{3}{*}{$\begin{array}{l}\text { Oferta y modalidad } \\
\text { productiva }\end{array}$} & Tipo de producto & - Tipo de producto generado \\
\hline & Modalidad productiva & - Modalidad de producción/ ejecución de los productos \\
\hline & $\begin{array}{l}\text { Participación de } \\
\text { familias }\end{array}$ & $\begin{array}{l}\text { - Participación de las familias beneficiarias en las diferentes } \\
\text { etapas del programa o proyecto }\end{array}$ \\
\hline
\end{tabular}

Fuente: elaboración propia, 2011. 
comunicación entre los actores político-sociales (...), y orientan los planes y decisiones hacia mejores prácticas de gestión pública (en materia socio-habitacional)"19. Sus atributos y categorías analíticas pueden así ser utilizados tanto para examinar políticas, o bien transformarse en principios normativos para diseñar políticas consistentes con este nuevo enfoque de gestión local de lo socio-habitacional.

\section{Descripción analítica y operacionalización de cada dimensión en variables e indicadores}

\section{CARACTERIZACIÓN INICIAL DEL MUNICIPIO:}

Cada municipio requiere realizar inicialmente y de acuerdo al período temporal considerado, una caracterización inicial, conformada por datos e información disponible a partir de fuentes oficiales. Esta caracterización inicial permanecerá estable para los diferentes programas o proyectos sociohabitacionales que se analicen para un mismo municipio, en un mismo período considerado.

Su inclusión resulta de alta relevancia dado que dicha caracterización constituye la base de análisis

19 Arnoletto et al, 2004. contextual del municipio, ya que permite establecer con claridad los atributos que lo identifican e individualizan. A partir de ellos, es posible evaluar el grado de adecuación de las líneas políticas vigentes o por desarrollar, y especificar recomendaciones que podrían o deberían ser tenidas en cuenta a nivel de programas o proyectos, advirtiendo aciertos u omisiones.

Los ítems seleccionados para definir la caracterización inicial del municipio son los siguientes:

- Denominación municipal: nombre del municipio en cuestión.

- Período considerado: expresado en años o en períodos interanuales.

- Caracterización geográfica: refiere a la ubicación regional, provincial y departamental de la localidad en cuestión. Dicha caracterización facilita la comparación intermunicipal sobre la base de un mapeo de una determinada zona o región.

- Caracterización demográfica: permite identificar el volumen poblacional y la cantidad de hogares de la ciudad en el período considerado.

Dichos datos constituyen la base para luego determinar mediante comparación la situación socio-económico-habitacional de personas y hogares. También facilita la comparación 
intermunicipal sobre la base de un mapeo de una determinada zona o región en base a la escala poblacional.

- Caracterización socio-económica: permite identificar la incidencia de la pobreza en la localidad de acuerdo a los indicadores de medición habituales en la región.

Esta caracterización facilita la identificación y el desarrollo de acciones habitacionales diversificadas, a fin de satisfacer las necesidades de los sectores identificados, y evaluar si estas acciones se adecuan a las capacidades y necesidades de los diferentes sectores de la localidad.

- Caracterización económico-laboral: permite especificar la conformación de la estructura productiva, su desempeño y los factores que intervienen en su comportamiento. En esta caracterización se solicita la especificación de la población económicamente activa así como las actividades económicas predominantes, el tipo o rama de oficios ligado a la zona, y la tasa de desempleo de la ciudad.

Diferentes modalidades productivas y constructivas en las intervenciones socio-habitacionales pueden potenciar o inhibir procesos de desarrollo local, estimulando que las externalidades de toda intervención habitacional redunden en beneficios a la comunidad local o, por el contrario, sean extraídas y capitalizadas por agentes externos sin ninguna retroalimentación para la localidad. Por ello, esta caracterización permite sentar las bases para posibles articulaciones entre políticas habitacionales y políticas productivas y de empleo, mediante la elección de modalidades productivas y constructivas adecuadas al perfil socio-económico local y la articulación/potenciación de empresas locales con la consecuente promoción del empleo y el desarrollo local.

- Caracterización educacional: refiere a la oferta educativa en la ciudad y el nivel educacional o de instrucción alcanzado por la población. Esta caracterización complementa la caracterización social, y permite evaluar la adecuación de las modalidades productivas y constructivas al nivel educativo de las comunidades consideradas. También hace visibles los centros educativos o de formación que pueden complementarse a las acciones habitacionales que se encaren, potenciando capacidades existentes y mejorando las capacidades de empleabilidad.

- Caracterización sanitaria: complementa la caracterización social de la localidad, ya que revela una aproximación a las condiciones de vida de la población. Se establece con el dato del tipo de cobertura de salud del total de la población, a partir del registro del porcentaje poblacional con cobertura de salud pública o privada, la tasa de mortalidad infantil local o departamental, el registro de las enfermedades 
más frecuentes y la identificación de la oferta de servicios sanitarios en la ciudad.

- Caracterización socio-vincular: permite identificar las organizaciones e instituciones relevantes en la ciudad por tipo, tanto como la acción colectiva y de cooperación, "como indicador de la presencia de manifestaciones concretas de producciones colectivas, expectativas de organización e impacto social de la cooperación"20.

Siguiendo a Grootaert ${ }^{21}$, intenta advertir en qué medida las personas trabajan junto a otros para alcanzar un objetivo común, indicando el nivel de movilización colectiva y el nivel de auto-organización de una comunidad. "Una sociedad que posee mayor cantidad de personas con expectativas favorables de cooperación, tanto en la espera de reciprocidad de cooperación cuanto en el impacto comunitario de su aporte, indicaría mayor predisposición a efectuar acciones colectivas que aquellas sociedades en las que las personas piensan que este tipo de asociaciones no aporta beneficios sustanciales a la comunidad ${ }^{22}$. Sienta, además, las bases para plantear posibles articulaciones interactorales en el marco de programas o proyectos socio-habitacionales.

20 Ibíd.

21 Grootaert et al, 2003

22 Arnoletto et al, 2004.
- Caracterización habitacional: se refiere al "registro del capital físico del que dispone una localidad, entendido como estructura mínima de las viviendas y los servicios con los que cuentan los habitantes de una ciudad"23. Se define a partir de la explicitación del porcentaje de hogares particulares por calidad de materiales de la vivienda y porcentaje de hogares hacinados, así como la dotación de infraestructura y servicios urbanos existentes en la localidad.

Esta caracterización permite dar cuenta de las condiciones de habitabilidad y de vida de la comunidad, tanto cuantitativa como cualitativamente, y facilita evaluar si las acciones habitacionales se adecuan a satisfacer las necesidades habitacionales locales.

- Caracterización político-institucional: permite identificar "el potencial de los gobiernos o administraciones municipales para orientar el desarrollo local, a partir de la cooperación o asociación y la gestión político-administrativa de las estructuras orgánicas y plantas burocráticas" 24 .

Los ítems considerados resultan: la forma de gobierno; la estructura política del mismo; el nivel local de gestión asociado con otros niveles de gobierno y actores sociales (medido a

$\begin{array}{ll}23 & \text { Ibíd. } \\ 24 & \text { Ibíd. }\end{array}$ 
través de la vigencia legal de convenios de asociación con los mismos); la situación económico-financiera del municipio (según ejecución presupuestaria del año inmediato anterior); la capacidad de gestión municipal (en función de la existencia o no de ordenanzas que determinen los cargos políticos y procedimientos administrativos, así como de ordenanzas orientadas a regular el territorio) y de sus recursos humanos (medido en relación a la existencia de ordenanzas que regulan el ingreso y la carrera administrativa por concurso, y su capacitación permanente) $)^{25}$.

Luego de la caracterización municipal necesaria como marco contextual de referencia del monitoreo o evaluación, el conjunto de indicadores a especificar por cada programa o proyecto sociohabitacional que se analice se explicitan a partir de variables vinculadas a dimensiones de proceso y dimensiones de resultados del programa o proyecto en cuestión.

\section{DIMENSIONES, VARIABLES E INDICADORES DE PROCESO}

Estas dimensiones, variables e indicadores permiten dar cuenta del proceso general de gestión. Su inclusión y consideración responde a que "las claves del modelo deben encontrarse no solo en los

25 Ibíd. rasgos de las soluciones que debe producir, adecuadas a los requerimientos y prioridades funcionales y a los hábitos cotidianos de quienes van a hacer uso de esas soluciones, sino también en los modos de gestión y de operación y en las estructuras organizativas e institucionales impresas en el modelo (...) de tal forma que la gestión misma de la solución habitacional sea experimentada como un cambio de reglas de juego, como un proceso de transición formativa y restauradora hacia una condición de integración favorable, no solo física, sino también social (e institucional) transformadora dentro de la estructura de la ciudad moderna"26.

Entre las seleccionadas como constitutivas del sistema de indicadores de gestión propuesto se encuentran:

- Estructura conceptual de abordaje del problema: la adopción de una determinada noción o concepto implica necesariamente una toma de posición ideológica, la cual condiciona no solo los enfoques teóricos adoptados sino las acciones y resultados que inspirados en dichos enfoques puedan alcanzarse.

A partir de la consideración del concepto como condicionante previo de la acción, definir la vivienda resulta un paso ineludible si se desean analizar las acciones que en esta materia se han desarrollado o deberían desarrollarse, ya que

26 Pelli, 1994. 
de acuerdo a cómo la concibamos (como objeto o unidad física o como proceso y como hábitat) serán los postulados teóricos y empíricos sobre los cuales centraremos nuestro análisis. Conceptualizar la vivienda como proceso complejo y como hábitat implica reconocer que en ella se interrelacionan variados aspectos y actores que hacen a la unidad habitacional y a su articulación al espacio urbano y/o territorio circundante, lo cual conlleva incluir o al menos no ignorar dimensiones económicas, sociales, culturales y políticas de los habitantes. Estos postulados teóricos y empíricos son los que se plasman a través de objetivos generales, objetivos específicos y metas a la hora de definir un programa o proyecto. Por tal razón, se entiende por estructura conceptual de abordaje la precisión de objetivos generales y particulares que se persiguen con el programa o proyecto, así como también cada una de las metas concretas propuestas para materializarlos, respondiendo a las intenciones propias de la institución y a su concepción de la forma en la que debe abordarse la problemática.

Un programa o proyecto que se oriente hacia una gestión integral y multiactoral debería evitar acciones reduccionistas, incluyendo objetivos y metas que trasciendan la vivienda como objeto físico-constructivo, a fin de posibilitar (o al menos no inhibir) en toda acción habitacional el desarrollo de todas las capacidades humanas.
En base a esta conceptualización, las variables e indicadores seleccionados resultan los objetivos y metas del programa o proyecto, discriminando sus tipos.

- Desarrollo temporal: se lo concibe como la serie de acciones que tuvieron, tienen o tendrán lugar a lo largo del programa o proyecto, consideradas indispensables en la consecución de las metas propuestas, incluyendo plazos empleados y la forma en que estas acciones se ordenan en el tiempo. Es decir, reúne en su conceptualización actividades, plazos y secuencias.

Las etapas posibles de ser desarrolladas son:

- Etapa decisional y de asignación de recursos: se obtiene la decisión política de dar inicio al programa o proyecto, se firman los acuerdos previos, se gestionan los fondos de financiamiento, se aprueban las ordenanzas que regirán la implementación del proyecto, se aprueban los decretos de asignación de personal responsable y la afectación de fondos, se adquieren o afectan las tierras y se institucionalizan los procedimientos necesarios para implementar el programa o proyecto en cuestión.

- Etapa motivacional, de capacitación y transferencia: etapa transversal a todo el desarrollo del programa o proyecto, constituida a partir de la organización de una serie de 
talleres o instancias colectivas que permiten garantizar el involucramiento de los beneficiarios en la planificación, formulación y gestión del proyecto, elección y transferencia de tecnologías, capacitación en oficios, jornadas de socialización y evaluación de lo realizado.

- Etapa de diseño, planificación y programación: ejecutada paralelamente con la etapa decisional y de asignación de recursos, aquí se da la elaboración definitiva del proyecto. En ella también se especifican los requisitos básicos a cumplir por los beneficiarios para poder insertarse en el programa o proyecto; se produce el ajuste de documentación técnica y se definen las alternativas constructivas y productivas. Esta etapa culmina con la elevación de la propuesta a las entidades locales competentes para su aprobación y posterior elevación o presentación del proyecto ante entidades financiadoras.

- Etapa diagnóstica: ejecutada paralelamente con la etapa de diseño, planificación y programación, acá se da el estudio y el análisis de datos estadísticos de la problemática o situación particular a atender por el programa o proyecto, actualizando datos sociodemográficos, habitacionales y urbanos. En ella no solo se determinan los criterios de selección y reemplazo de las familias beneficiarias, sino también los recursos humanos a afectar, las posibles empresas tercerizadoras de obra y las posibles fuentes de financiación.

- Etapa de concreción y ejecución: se extiende desde la ejecución de trabajos previos hasta la inauguración oficial de las obras, entrega de las mismas y ocupación por parte de las familias. En ella se concretizan las obras planificadas según las modalidades productivas y contractivas especificadas en el programa o proyecto.

- Etapa de evaluación y retroalimentación: es transversal al desarrollo de todo el programa o proyecto, a partir de instancias de seguimiento y monitoreo, y/o bajo modalidades ex post mediante entrevistas o encuestas.

- Etapa de pos-ocupación o pos-proyecto: etapa de seguimiento posterior a la ocupación de las familias donde no solo se trabaja la inserción de las mismas a la nueva situación habitacional sino cuestiones como el uso, mantenimiento, derechos y obligaciones con respecto a esta nueva situación. En ella también se potencia la generación de nuevas iniciativas y proyectos complementarios al ejecutado.

- Instancias de recupero: aquí forman parte las estrategias de recupero planteadas previamente a la concreción de las acciones 
planificadas (ahorro previo o aporte inicial) o bien, posteriormente a las mismas (recupero o reintegro), a fin de garantizar el reintegro total o parcial, por parte de los beneficiarios del programa o proyecto, de los fondos y recursos puestos en juego para su desarrollo.

Programas o proyectos que avancen hacia una gestión integral y multiactoral conllevan tiempos no estrictamente condicionados a los plazos de obra física, sino que suponen plazos sujetos a los procesos socio-políticos.

En base a esta conceptualización, la variable e indicadores seleccionados como relevantes, resulta el tipo de etapas verificadas, bajo la caracterización explicitada.

- Integralidad de las acciones: en la cuestión habitacional (como hecho antropológico, dinámico e histórico) se interrelacionan varios aspectos: el espacial, el económico, el social, el político-institucional y el plano cultural27. Decimos estar frente a una problemática y no frente a un problema, ya que "los problemas tienen una solución parcelaria, pueden ser abordados fácilmente desde una disciplina particular. En cambio, la problemática es diversa y compleja, precisa de un enfoque holístico, integrador,

27 Cortés, 1995. buscando que las acciones humanas en sectores concretos, lejos de generar efectos negativos en otros sectores, favorezcan la generación de procesos para la transformación social"28. Es decir, la problemática de la vivienda debe necesariamente ser abordada desde diferentes disciplinas, buscando no precisamente atenuar el "problema" o "resolver permanentemente los problemas" sino "ir a las causas", y para ello resulta necesario conocer y acometer la problemática en su globalidad, ya que la vivienda "es un conjunto de problemas autoimplicados que como tales contienen la potencialidad conferida por el propio desequilibrio que los define"29.

"Cualquier análisis de las nuevas proposiciones teóricas de entender la pobreza no puede dejar de identificar el concepto de integralidad o multidimensionalidad como uno de sus principales atributos. Las numerosas carencias que se registran a nivel socio-habitacional se caracterizan por una simultaneidad que se manifiesta explícitamente en las ciudades, especialmente en los asentamientos humanos irregulares"30. "La pobreza urbana es un todo indivisible (...), sin embargo, para las instituciones (...) es una condición a la que se responde con una diversidad de programas (...) sectoriales (...). Hay

28 Gómez, 1995.

29 Cortés, 1995.

30 Ramírez, 2002. 
una marcada desconexión entre la unidad de la experiencia y la diversidad institucional de las respuestas"31.

Desde este enfoque, esto supone verificar la consideración de otros objetivos y/o acciones complementarias a lo habitacional, respondiendo así a la concepción de la vivienda como configuración de servicios que, superando la visión meramente física, la concibe como parte de un conjunto mayor e integral de servicios dirigido a dar satisfacción a las diversas necesidades del hombre (alimentación, educación, hábitat, trabajo, participación, etc.), cada una de las cuales presenta su propia problemática específica y sectorial.

Aunque la solución a estas necesidades varía en cada cultura, desde este enfoque, un programa o proyecto que se oriente hacia una gestión integral y multiactoral tendría que tender a ser integral, o por lo menos la solución de una o dos necesidades no debería entorpecer sino facilitar la solución de las otras. Ello supone, a su vez, la integración disciplinaria y la articulación formalizada de diferentes áreas y competencias; es decir, la multidimensionalidad o integralidad adopta también el concepto

31 UN-HABITAT, 1996. de multisectorialidad, a fin de integrar simultáneamente las actividades de muchos de los sectores en que tradicionalmente se ha dividido el trabajo de las instituciones públicas y privadas: vivienda, salud, educación, empleo y otros.

Si bien podrían incorporarse muchas calificaciones a este atributo, para la evaluación positiva de un programa o política se considera como suficiente la inclusión de iniciativas simultáneas a las de viviendas y participación de otros sectores. Por tales motivos, las variables e indicadores seleccionados como determinantes del nivel de integralidad de las acciones promovidas resultan ser el tipo de necesidades satisfechas por el programa o proyecto en cuestión $^{32}$; los objetivos y metas del programa o proyecto; los proyectos complementarios al habitacional, y la capacidad de gestión integral instalada en el municipio, operacionalizada esta última a través de la consideración de las áreas municipales y disciplinas vinculadas o afectadas al programa o proyecto; la formalización de la articulación entre estas áreas; la existencia de procedimientos compartidos; y las disciplinas involucradas.

32 Según Max Neef, existen muchas maneras de clasificar necesidades. La interrelación entre necesidades, satisfactores y bienes económicos es permanente y dinámica, y a través de ella se convierten en determinantes de los estilos de desarrollo. 
- Participación y articulación de actores: la solución de los problemas urbanos y habitacionales resultan lo suficientemente urgentes en nuestros contextos para movilizar a todos los sectores sociales, y por ser un punto de concurrencia para la participación de los actores interesados, como espacio de concertación y negociación equitativa, donde resulta clave la participación popular concebida como el protagonismo de los pobladores entre relaciones asimétricas de poder.

Dar cuenta de la participación actoral en un programa o proyecto habitacional supone reconocer el involucramiento de los diferentes actores sociales en las distintas etapas del proceso, tomando decisiones en conjunto y compartiendo con el estado la responsabilidad solidaria de mejorar las condiciones de vida y de inserción urbana de las poblaciones, superando el papel de simples beneficiarios o simples medios para reducir $\operatorname{costos}^{33}$. Lograrlo requiere de un largo trabajo de base, de promoción, consenso, madurez y organización social que lleve a cuestionar la simple lógica de eficiencia por sí misma.

Por las razones expuestas, esta variable se plantea a partir del carácter "relacional" o "interactoral" que han ido adquiriendo los gobiernos locales durante las últimas décadas ("gestión asociada"), donde la solución para los

33 Romero y Mesías, 1999. complejos problemas contemporáneos se intenta "desde el equilibrio entre los varios marcos institucionales involucrados: el estatal, el mercado y el público no-estatal, adoptando el concepto de estado-red, capaz de aglutinar varias lógicas y sujetos sociales para hacer frente a los escenarios actuales" ${ }^{\prime \prime}$.

Por ello, esta variable revela la capacidad del municipio para generar espacios de trabajo interdisciplinario e inter-áreas, de la misma manera que manifiesta el grado de acercamiento entre éste y la sociedad, detectando si se han creado o reforzado espacios de involucramiento y asociación a distintas escalas. A saber:

- Escala intra-municipal o entre diferentes áreas municipales o entre las diferentes áreas de la propia estructura institucional.

- Escala inter-gubernamental o entre diferentes niveles de gobierno (nacional, provincial y municipal), a fin de detectar la complementación o superposición de recursos y líneas de acción.

- Escala inter-institucional o entre el municipio y diversos actores sociales: promovida como forma de potenciar recursos existentes y disponibles por los distintos actores involucrados, tanto a nivel de financiamiento, como de coordinación/administracióny de ejecución.

34 Aguilar Villanueva, 2006. 
Esta escala verifica la forma en que los procesos orientados por la ganancia, los comunitarios, los estatales y los políticos, articulan sus lógicas y coparticipan en el proceso de construcción de los fenómenos socio-habitacionales, cuyo sentido nunca está predeterminado sino que depende en cada caso de cómo dichos actores ejerzan sus roles.

Un programa o proyecto orientado hacia una gestión integral y multiactoral debería caracterizarse por estimular mayores y mejores relaciones de articulación actoral, a partir de la institucionalización de instancias de gestión asociada y de equipos interdisciplinarios, como estrategias de aporte y confluencia de recursos, procurando así avances en las negociaciones y complementaciones entre actores, a fin de reducir la arraigada cultura verticalista, centralizada y clientelista.

Los indicadores definidos en base a las variables seleccionadas resultan así ser los actores sociales involucrados (intermunicipales, intergubernamentales e interinstitucionales), y el tipo de articulación predominante entre ellos (de demanda, de subordinación, de negociación o de complementariedad) ${ }^{35}$; la existencia de espacios de involucramiento y asociación generados, capitalizados o reforzados en el marco del programa o proyecto; su grado de institucionalización efectiva; y la participación de los beneficiarios en las diferentes etapas del programa o proyecto.

35 Rodríguez et al, 2001
- Capacidad institucional instalada: poner en práctica formas innovadoras de gestión demanda también desarrollar nuevas capacidades institucionales.

Una de las deficiencias más notables a la hora de encarar acciones que apuesten hacia opciones integrales y multiactorales resulta la debilidad de capacidad institucional (organizacional, técnica, administrativa y de evaluación) disponible e instalada en el municipio, que le permita poner en marcha abordajes innovadores acordes a las necesidades complejas existentes en términos socio-habitacionales.

Es importante tener en cuenta que la capacidad institucional excede el mero fortalecimiento de habilidades y técnicas individuales, ya que involucra también al entorno institucional y organizacional en el cual los individuos toman decisiones y diseñan e implementan políticas públicas.

Según Oszlak y Orellana ${ }^{36}$, "entre lo que las organizaciones ambicionan hacer y lo que efectivamente consiguen realizar existen diversos obstáculos que impiden o dificultan la realización de tareas conducentes al logro de los resultados buscados". Estos obstáculos constituyen una brecha que Tobelem denomina "déficit de capacidad institucional" 37 .

36 Oszlak y Orellana, 1993.

37 Tobelem, 1992. 
Según estos autores, los déficits de capacidad institucional más frecuentes pueden agruparse en las siguientes categorías:

- Institucionales propiamente dichos (relacionados con normas y reglas de juego que condicionan o impiden la ejecución de tareas).

- De coordinación interorganizacional e interjurisdiccional.

- De organización interna y asignación de tareas.

- De capacidad financiera y física de la organización.

- De los sistemas de recursos humanos, políticas de personal e incentivos.

- De capacidad de los responsables de ejecutar las tareas.

Para programas o proyectos orientados hacia una gestión integral y multiactoral superadora, esta variable se encuentra íntimamente relacionada con las dimensiones de proceso mencionadas, referidas a la estructura conceptual de abordaje del problema, el nivel de integralidad de las acciones, el grado de participación y articulación de actores, y el nivel de condicionamiento político existente.

Lo que le compete a una gestión integral y multiactoral es potenciar los recursos humanos disponibles e institucionalizar procedimientos que favorezcan estrategias de mejoramiento de la gestión socio-habitacional local, en torno a la obtención, coordinación y monitoreo tanto de recursos como de procesos conducentes a la concreción y retroalimentación de los programas o proyectos específicos.

Por ello, las variables e indicadores considerados relevantes son: el nivel de capacidad técnica instalada -a partir de la consideración de su nivel de especialización, dedicación horaria asignada al programa o proyecto, $y$ formalización de su designación-; la capacidad administrativa instalada -a partir del origen de los recursos invertidos en el programa o proyecto, y la existencia de procedimientos formalizados que garanticen el registro de todas las operaciones (administrativas, económicas, sociales) del programa o proyecto-; y el nivel de capacidad de evaluación instalada, en función de la existencia de instancias formales de evaluación y retroalimentación del programa o proyecto.

- Condicionamiento político: como se mencionó, los municipios todavía mantienen una dependencia grande con los niveles superiores de gobierno o los entes financiadores, principalmente a causa de la falta de recursos y de la escasa voluntad política en torno a modalidades propias o mixtas. En este sentido, entre las fuerzas o condicionantes claves detectadas en 
todo proceso de gestión, la dimensión política en el desarrollo de proyectos o programas resulta una de las principales, tanto por su poder inductor cuando se cuenta con ella, como por su carácter netamente inhibidor si se carece de la misma.

El grado de condicionante político es aquí considerado como el nivel de influencia y determinación de acciones que los lineamientos y avales político-programáticos (tanto locales como de niveles superiores de gobierno) poseen sobre el programa o proyecto.

Evalúa, además, el grado de sustento organizativo-legal que posee la experiencia (grado de institucionalidad del mismo).

Para programas o proyectos orientados hacia una gestión integral y multiactoral, esta dimensión está caracterizada por la correlación y coherencia con los lineamientos políticoprogramáticos provistos por las políticas locales o de niveles superiores de gobierno de los cuales forman parte, pero no son aceptados bajo subordinación absoluta y aceptación sin objeciones, sino que se registran adaptaciones y ajustes a las necesidades que las situaciones particulares puedan requerir.

A nivel normativo-organizacional, se caracterizan por contar con equipos formalizados de trabajo interdisciplinario e inter-áreas dedicados al hábitat social como problemática específica, e inclusión de instrumentos legales ad-hoc o flexibilizaciones en los habituales, que favorecen la gestión asociada e integral del proyecto. Esta condición se traduce en la existencia de instancias de negociación y adaptaciones particulares a los lineamientos operativo-programáticos que el programa o proyecto exige.

Así se intenta dar cuenta del nivel de anclaje que el programa o proyecto posee a nivel organizacional y normativo-legal, como garantías de sustento e institucionalidad de las iniciativas analizadas.

Por ello, las variables e indicadores considerados relevantes son: la correlación y coherencia con los lineamientos político-programáticos provistos por las políticas, de las cuales los programas o proyectos analizados forman parte; el marco normativo-organizacional de inserción de los mismos, a partir de la consideración de la conformación de equipos ad-hoc de trabajo interdisciplinario e inter-áreas dedicados al hábitat social; el grado de formalización de estos equipos; y el diseño e incorporación de instrumentos legales ad-hoc o flexibilizaciones en los habituales que favorezcan la gestión asociada e integral. 


\section{DIMENSIONES, VARIABLES E INDICADORES DE RESULTADOS}

Los enfoques a los cuales se adhiere y los procesos que éstos ponen en marcha, condicionan las acciones y resultados que inspirados en dichos enfoques y procesos pueden alcanzarse. Por tal motivo, estas dimensiones, variables e indicadores intentan dar cuenta de los resultados alcanzados tras los procesos promovidos.

- Nivel socio-económico de los beneficiarios: es la condición material y cultural de vida del grupo social de la comunidad objetivo del programa o proyecto en cuestión.

Si bien se tiende a incluir a familias de variados sectores sociales, en los programas y proyectos de hábitat social se priorizan las familias de escasos recursos.

Las variables e indicadores determinantes de esta condición están relacionados con la ubicación geográfico-territorial inicial de la comunidad objetivo; el nivel educacional alcanzado; el nivel económico de los hogares en cuestión; la situación laboral de los jefes de hogar; y la situación habitacional inicial de los hogares.

- Implantación territorial: se refiere a la modalidad en que el programa o proyecto se asienta en el territorio y el tipo de localización y radicación que favorece.
En programas o proyectos orientados hacia una gestión integral y multiactoral, la unidad de implantación en el territorio son los conjuntos habitacionales de mediana y pequeña escala, de carácter progresivo, con equipamiento e infraestructura cogestionada. Se busca evitar los traslados, por lo que se favorecen asentamientos intersticiales en terrenos vacantes en la trama urbana, o mediante estrategias de reurbanización, reordenamiento, mejoramiento o consolidación urbana, se evita romper redes de subsistencia, así como favorecer mayor mixtura de usos e integración social con otros sectores de la ciudad.

Las variables e indicadores seleccionados son: la escala de la intervención urbano-habitacional propuesta en base a cantidad de soluciones habitacionales planteadas; y el tipo de radicación promovida entre las familias involucradas, a partir de la consideración de la ubicación final de la comunidad en relación a su ubicación inicial.

- Oferta y modalidad productiva: los productos y modalidades productivas pueden favorecer el desarrollo de capacidades, recursos o procesos de inserción socio-laboral y urbana, o bien, pueden inhibirlos. De acuerdo al tipo de producto habitacional o urbano que se proponga y al modo en que éste se genere, los 
resultados en términos de procesos resultan diferentes.

En programas o proyectos orientados hacia una gestión integral y multiactoral, las modalidades productivas y constructivas son variadas según las necesidades existentes, los recursos, propuestas y conocimientos regionales y locales, predominando las opciones que capitalizan los aportes de las familias beneficiarias. Por ello, se propicia la construcción de soluciones habitacionales variadas con sistemas tecnológicos también variados (admitiendo alternativos), ejecutadas para el caso de sectores de escasos recursos con modalidades productivas y constructivas que favorezcan una mejor o mayor incorporación de los beneficiarios al mercado laboral, generalmente por ayuda mutua o esfuerzo propio.

Los indicadores de referencia se encuentran así vinculados a las siguientes variables: tipo de producto generado; modalidad de producción o ejecución de dichos productos; y participación de las familias beneficiarias en las diferentes etapas del proceso.

Estas dimensiones, variables e indicadores propuestos y desarrollados no agotan, por supuesto, las posibilidades de análisis y nuevas proposiciones locales complementarias.

\section{Instrumentos y fuentes de información exigidos}

A fin de recoger los datos necesarios, se propone un único instrumento de recolección de los datos solicitados por el índice en los respectivos indicadores que lo componen, a fin de facilitar su carga ganando operatividad. Sus fuentes de información y recolección son las que a continuación se detallan:

Para caracterización del municipio en cuestión:

- Censo Nacional de Población y Vivienda.

- Registros locales de áreas especificadas.

- Registros regionales de ítems especificados.

- Encuesta poblacional ad-hoc.

Para programas o proyectos desarrollados o en curso:

- Informes de los programas o proyectos desarrollados o en curso.

- Publicaciones y registros escritos o audiovisuales específicos que permitan la reconstrucción de los procesos.

- Registro de ordenanzas, decretos o designaciones oficiales.

- Registro de inscritos o familias beneficiarias. 
- En caso de ser necesario, por no contar con los datos requeridos, se sugiere recurrir a entrevistas semiestructuradas y cuestionarios a técnicos, funcionarios y actores locales involucrados en los procesos analizados.

Para programas o proyectos a desarrollar:

- Presentación oficial del programa o proyecto.

- Registro de inscritos o familias beneficiarias.

- En caso de ser necesario, por no contar con los datos requeridos, se sugiere recurrir a entrevistas semiestructuradas y cuestionarios a técnicos, funcionarios y actores locales involucrados en el diseño de los programas o proyectos en cuestión, exigiendo que dichas especificaciones queden asentadasenlapresentación oficialde losmismos.

\section{Método de evaluación}

El método de evaluación propuesto consiste en ponderar las dimensiones, variables e indicadores, asignando valores entre 1 y 10 , de manera discreta, ubicando en los extremos los atributos que reflejan la total adecuación y coherencia con los modelos descritos (modelo tradicional y modelo integral y multiactoral). Los valores intermedios reflejan los atributos híbridos presentes en los procesos evaluados.
En los casos en que la asociación de atributos muestra una gradualidad creciente hacia un modelo específico, se utiliza una escala incremental lineal por intervalos (ecuación de una recta) para expresar numéricamente dicha tendencia.

Para los indicadores donde se debe reflejar la tendencia de las características de un grupo determinado (como grupos técnicos involucrados), se ponderan los factores especificados por valores relativos previamente definidos.

Dado que el alcance de esta ponencia solo se limita a la identificación, descripción y justificación de indicadores integrados que faciliten el monitoreo y la evaluación de la gestión local del hábitat en ciudades no metropolitanas desde una perspectiva integral y asociativa del hábitat social, no se desarrollan aquí en detalle los parámetros de ponderación para cada una de las dimensiones, variables e indicadores específicos.

Un posterior trabajo permitiría exponer dicha metodología, complementando el desarrollo de los indicadores aquí expuestos. Sin embargo, a modo de ejemplo, se operacionalizan y detallan a continuación las formas de medición de las dimensiones "Integralidad de las acciones" y "Participación y articulación de actores". 


\section{TABLA 3: OPERACIONALIZACIÓN DE LA DIMENSIÓN “INTEGRALIDAD DE LAS ACCIONES".}

Dimensión 3: InTegralidad de Las acciones.

Variable 3.1: Necesidades SATISFECHAS.

Indicador 3.1.a: Necesidades humanas QUe Se intentan Satisfacer Con el Programa/Proyecto.

\section{Categoría de análisis Situaciones posibles}

Protección/ Habitabilidad

item seleccionado

ítem seleccionado

\begin{tabular}{|c|c|c|}
\hline Subsistencia & \multirow{8}{*}{$\begin{array}{c}\text { Sin ninguna selección en este } \\
\text { grupo }\end{array}$} & \multirow{8}{*}{$\begin{array}{c}1 \text { o más ítems seleccionados de } \\
\text { este grupo }\end{array}$} \\
\hline Afecto & & \\
\hline Entendimiento & & \\
\hline Participación & & \\
\hline Ocio & & \\
\hline Creación & & \\
\hline Identidad & & \\
\hline Libertad & & \\
\hline Valoraciones & 1 & 5 a $10(1)$ \\
\hline
\end{tabular}

VARIABle 3.2 Y 3.3: OBJetivos y METAS/PROYECTOS COMPLEMENTARIOS.

INDICADORES 3.2.A, 3.2.B Y 3.3.A: EXISTENCIA DE OTROS OBJETIVOS/ METAS/ PROYECTOS COMPLEMENTARIOS.

Categoría de análisis Situaciones posibles

Objetivos/Metas/ Proyectos urbanos ítem seleccionado

ítem seleccionado

Objetivos/Metas/Proyectos

sociales-comunitarios
Objetivos/ Metas/ Proyectos legales

Objetivos/Metas/ Proyectos educativos-culturales

Objetivos/Metas/Proyectos sanitarios

Sin ninguna selección en este grupo

Objetivos/Metas/ Proyectos productivos-laborales

Otros

\begin{tabular}{llll}
\hline Valoraciones & 1 & 1 & 5 a 10(1) \\
\hline
\end{tabular}


Variable 3.4: Capacidad de gestión integral instalada en el municipio. INDICADOR 3.4.A: ÁreAs O REPARTICIONES VINCULADAS O AFECTADAS.

\begin{tabular}{|c|c|c|}
\hline Categoría de análisis & \multicolumn{2}{|c|}{ Situaciones posibles } \\
\hline Planeamiento o desarrollo urbano & ítem seleccionado o no & ítem seleccionado o no \\
\hline Edificaciones privadas & ítem seleccionado o no & ítem seleccionado o no \\
\hline Obras y servicios públicos & ítem seleccionado o no & ítem seleccionado o no \\
\hline Promoción o desarrollo social & ítem no seleccionado & \multirow{3}{*}{$\begin{array}{l}1 \text { o más ítems seleccionados de } \\
\text { este grupo (se ponderan el doble) }\end{array}$} \\
\hline Desarrollo económico, producción o empleo & ítem no seleccionado & \\
\hline Área legal o fiscalía municipal & ítem no seleccionado & \\
\hline Área administrativo-contable & ítem seleccionado o no & ítem seleccionado o no \\
\hline Compras y suministros & ítem seleccionado o no & ítem seleccionado o no \\
\hline Catastro municipal & ítem seleccionado o no & \multirow{3}{*}{$\begin{array}{c}10 \text { más ítems seleccionados de } \\
\text { este grupo }\end{array}$} \\
\hline Prensa y protocolo & ítem seleccionado o no & \\
\hline Otras & ítem seleccionado o no & \\
\hline Valoraciones & 1 & 5 a $10(1)$ \\
\hline
\end{tabular}

Indicador 3.4.B: Formalización de LA ARTICULACIÓn ENTRE ÁREAS Y dE PROCEDIMIENTOS.

\begin{tabular}{lcc} 
Categoría de análisis & \multicolumn{2}{c}{ Situaciones posibles } \\
$\begin{array}{l}\text { Funcionamiento formalizado por designación oficial } \\
\text { (ordenanza, decreto, etc.) }\end{array}$ & ítem no seleccionado & ítem seleccionado \\
\hline Funcionamiento no formalizado o de hecho & ítem seleccionado & ítem no seleccionado \\
\hline Valoraciones & $\mathbf{1}$ & $\mathbf{1 0}$ \\
\hline
\end{tabular}


INDICADOR 3.4.C: DISCIPLINAS INVOLUCRADAS DURANTE EL PROCESO

\begin{tabular}{|c|c|c|}
\hline Categoría de análisis & Situacion & posibles \\
\hline $\begin{array}{l}\text { Ciencias de la ingeniería y de materiales (Arquitectura, Ingenierías, } \\
\text { Construcciones) }\end{array}$ & ítem seleccionado & ítem seleccionado \\
\hline Ciencias agrarias (Agronomía, Veterinaria) & ítem no seleccionado & \multirow{5}{*}{$\begin{array}{c}1 \text { o más ítems } \\
\text { seleccionados de } \\
\text { este grupo }\end{array}$} \\
\hline $\begin{array}{l}\text { Ciencias biológicas o de la salud (Ciencias Médicas, Biología, } \\
\text { Bioquímica) }\end{array}$ & ítem no seleccionado & \\
\hline $\begin{array}{l}\text { Ciencias exactas y naturales (Química, Física, Matemática, Ciencias de } \\
\text { la tierra, del agua y de la atmósfera) }\end{array}$ & ítem no seleccionado & \\
\hline $\begin{array}{l}\text { Ciencias sociales y humanidades (Derecho, Ciencias Políticas, } \\
\text { Psicología, Educación, Sociología, Trabajo social y Demografía) }\end{array}$ & ítem no seleccionado & \\
\hline Informática, computación y tecnología & ítem no seleccionado & \\
\hline $\begin{array}{l}\text { Ciencias económicas y de la administración (Economía, Contabilidad, } \\
\text { Ciencias de la gestión y de la Administración pública) }\end{array}$ & ítem seleccionado & ítem seleccionado \\
\hline Valoraciones & 1 & 5 a $10(1)$ \\
\hline
\end{tabular}

Fuente: elaboración propia, 2011.

\section{Variable 3.1: Necesidades satisfechas}

Indicador 3.1.a: Necesidades humanas que se intentan satisfacer con el programa o proyecto

Para este caso, la escala del intervalo de 5 a 10 corresponde a la recta de distribución siguiente:

Si hay en total 1 ítem seleccionado (x1), el valor correspondiente es 5 (yl).

Si hay en total 8 ítems seleccionados (x2), el valor correspondiente es 10 (y2).

Los valores intermedios responden a la ecuación de la recta siguiente:
Valoración $(y)=5 / 8 . N^{\circ}$ de ítems seleccionados $(x)+5$.

Método de ponderación: Matriz de asignación por atributos, de escala combinada (escala discreta (1) y escala de regresión lineal en intervalo de 5 a 10).

\section{VAriable 3.2 Y 3.3: ObJetivos y metas/ PROYeCtos COMPLEMENTARIOS}

Indicadores 3.2.a, 3.2.b y 3.3.a: Existencia de otros objetivos / metas / proyectos complementarios al habitacional.

Para este caso, la escala del intervalo de 5 a 10 corresponde a la recta de distribución siguiente: 
Si hay en total 1 ítem seleccionado (x1), el valor correspondiente es 5 (yl).

Si hay en total 6 ítems seleccionados (x2), el valor correspondiente es 10 (y2).

Los valores intermedios responden a la ecuación de la recta siguiente:

Valoración $(\mathrm{y})=\mathrm{N}^{\circ}$ de ítems seleccionados $(\mathrm{x})+4$.

Método de ponderación: Matriz de asignación por atributos, de escala combinada (escala discreta (1) y escala de regresión lineal en intervalo de 5 a 10).

\section{Variable 3.4: Capacidad de gestión integral instalada EN EL MUNICIPIO}

Indicador 3.4.a: Áreas o reparticiones vinculadas o afectadas

Para este caso, la escala del intervalo de 5 a 10 corresponde a la recta de distribución siguiente:

Si hay en total 1 ítem seleccionado (x1), el valor correspondiente es 5 (yl).

Si hay en total 9 ítems seleccionados (x2), el valor correspondiente es 10 (y2).

Los valores intermedios responden a la ecuación de la recta siguiente:

Valoración $(y)=5 / 8$ ( $\mathrm{N}^{\circ}$ de ítems seleccionados $(\mathrm{x})-1)+5$

100 revista invi № 77 / Mayo 2013 / Volumen № 28: 69-109
Método de ponderación: Matriz de asignación por atributos, de escala combinada (escala discreta (1) y escala de regresión lineal en intervalo de 5 a 10).

\section{Indicador 3.4.b: Formalización de la articula- ción entre áreas y de procedimientos}

Para este caso, el método de ponderación ha sido el siguiente:

Matriz de asignación por atributos, de escala discreta (1 y 10).

\section{Indicador 3.4.c: Disciplinas involucradas duran- te el proceso}

Para este indicador, la escala del intervalo de 5 a 10 corresponde a la recta de distribución siguiente:

Si hay en total 1 ítem seleccionado (x1), el valor correspondiente es 5 (yl).

Si hay en total 5 ítems seleccionados (x2), el valor correspondiente es 10 (y2).

Los valores intermedios responden a la ecuación de la recta siguiente:

Valoración (y) = 5/4 ( $\mathrm{N}^{\circ}$ de ítems seleccionados ( $\mathrm{x}$ )$1)+5$.

Método de ponderación: Matriz de asignación por atributos, de escala combinada (escala discreta (1) y escala de regresión lineal en intervalo de 5 a 10). 


\section{TABLA 4: OPERACIONALIZACIÓN DE LA DIMENSIÓN “PARTICIPACIÓN Y ARTICULACIÓN DE ACTORES".}

Dimensión 4: Participación y articulación de actores.

Variable 4.1: Actores involucrados.

Indicador 4.1.A: Actores SOCIaleS InVOLUCRAdOS EN El PROGrama o PROYECTO.

\begin{tabular}{|c|c|c|c|c|}
\hline Categoría de análisis & & Situacion & posibles & \\
\hline Planeamiento o desarrollo urbano & & & & \\
\hline Edificaciones privadas & & & & \\
\hline Obras y servicios públicos & & & & \\
\hline Promoción o desarrollo social & & & & \\
\hline Desarrollo económico, producción o empleo & Sin ninguna & 1 o más ítems & 10 más ítems & 1 o más ítems \\
\hline Área legal o Fiscalía municipal & selección en & seleccionados & seleccionados & seleccionados \\
\hline Área administrativo-contable & este grupo & de este grupo & de este grupo & de este grupo \\
\hline Compras y suministros & & & & \\
\hline Catastro municipal & & & & \\
\hline Prensa y protocolo & & & & \\
\hline Otras & & & & \\
\hline Organismos gubernam. internacionales & & & & \\
\hline Organismos gubernamentales nacionales & 10 más ítems & Sin ninguna & 10 más ítems & 1 o más ítems \\
\hline Organismos gubernamentales provinciales & seleccionados & selecclon en & $\begin{array}{l}\text { selecclonados } \\
\text { de este grung }\end{array}$ & $\begin{array}{l}\text { seleccionados } \\
\text { de este arung }\end{array}$ \\
\hline Organismos gubernam. de otros municipios & & & & \\
\hline Empresas locales, provinciales o nacionales & 10 más ítems & 1 o más ítems & Sin ninguna & 1 o más ítems \\
\hline $\begin{array}{l}\text { Asociaciones, grupos y/u organizaciones no } \\
\text { gubernamentales o comunitarias }\end{array}$ & $\begin{array}{l}\text { seleccionados } \\
\text { de este grupo }\end{array}$ & $\begin{array}{l}\text { seleccionados } \\
\text { de este grupo }\end{array}$ & $\begin{array}{l}\text { selección en } \\
\text { este grupo }\end{array}$ & $\begin{array}{l}\text { seleccionados } \\
\text { de este grupo }\end{array}$ \\
\hline Valoraciones & 1 & 1 & 1 & 5 a $10(1)$ \\
\hline
\end{tabular}


VARIABle 4.2: Espacios de aRTICULACIÓN.

INDICADOR 4.2.A: TIPO DE ARTICULACIÓN ENTRE LOS ACTORES SOCIALES.

\section{Categoría de análisis $\quad$ Situaciones posibles}

De demanda o clientelar (soluciones provistas por entidades de nivel superior, sin articulación de recursos existentes de los

ítem ítem no ítem ítem no ítem no actores intervinientes)

De subordinación (aceptación sin objeciones ni pedidos de adaptaciones a las soluciones que entidades de nivel superior derivan a seleccionado seleccionado seleccionado seleccionado seleccionado ámbitos inferiores)

De negociación (si bien existen articulaciones, se identifican actor/actores que definen decisiones y acciones, sobre las que luego se negocia)

De complementariedad (los diferentes actores planean y articulan acciones y recursos, participando activamente en las decisiones)

ítem no ítem ítem no ítem no ítem no

seleccionado seleccionado seleccionado seleccionado seleccionado

ítem no ítem no ítem no ítem ítem no

seleccionado seleccionado seleccionado seleccionado seleccionado

ítem no ítem no ítem ítem no ítem

seleccionado seleccionado seleccionado seleccionado seleccionado

INDICADORES 4.2.B Y 4.2.C:

ESPACIOS DE INVOLUCRAMIENTO Y ASOCIACIÓN GENERADOS / CAPITALIZADOS / REFORZADOS Y GRADO DE INSTITUCIONALIZACIÓN DEL/LOS ESPACIOS DE INVOLUCRAMIENTO Y ARTICULACIÓN ACTORAL.

\begin{tabular}{lccc} 
Categoría de análisis & \multicolumn{3}{c}{ Situaciones posibles } \\
\hline Sí & ítem no seleccionado & ítem seleccionado & ítem seleccionado \\
\hline No & ítem seleccionado & ítem no seleccionado & ítem no seleccionado \\
\hline Formal (con convenio u ordenanza) & $\begin{array}{c}\text { ítem seleccionado } \\
\text { o no }\end{array}$ & ítem no seleccionado & ítem seleccionado \\
\hline Informal o de hecho (sin convenio u ordenanza) & $\begin{array}{c}\text { ítem seleccionado } \\
\text { o no }\end{array}$ & ítem seleccionado & ítem no seleccionado \\
\hline Valoraciones & $\mathbf{1}$ & $\mathbf{7 , 5}$ & $\mathbf{1 0}$ \\
\hline
\end{tabular}


Indicador 4.2.D: Participación de familias beneficiarias en las etapas del PROGRama o PROYeCto.

\begin{tabular}{|c|c|c|c|}
\hline Categoría de análisis & & Situaciones posibles & \\
\hline En ninguna & Ítem seleccionado & Ítem no seleccionado & Ítem no seleccionado \\
\hline En etapa decisional y de asignación de recursos & Ítem no seleccionado & Ítem no seleccionado & \multirow{4}{*}{$\begin{array}{l}1 \text { o más ítems } \\
\text { seleccionados de } \\
\text { este grupo }\end{array}$} \\
\hline En etapa motivacional, capacitación y transfer. & Ítem no seleccionado & Ítem no seleccionado & \\
\hline En etapa de diseño, planificación y programación & Ítem no seleccionado & Ítem no seleccionado & \\
\hline En etapa diagnóstica & Ítem no seleccionado & Ítem no seleccionado & \\
\hline En etapa de concreción y ejecución & Ítem no seleccionado & \multirow{2}{*}{$\begin{array}{l}\text { Alguno de estos } \\
\text { ítems seleccionados }\end{array}$} & \multirow{2}{*}{$\begin{array}{c}\text { Alguno de estos } \\
\text { ítems seleccionados }\end{array}$} \\
\hline En instancias de recupero & Ítem no seleccionado & & \\
\hline En etapa de evaluación y retroalimentación & Ítem no seleccionado & Ítem no seleccionado & \multirow{2}{*}{$\begin{array}{l}1 \text { o más ítems } \\
\text { seleccionados de } \\
\text { este grupo }\end{array}$} \\
\hline En etapa de post-ocupación o pos-proyecto & Ítem no seleccionado & Ítem no seleccionado & \\
\hline Valoraciones & 1 & 1 & 5 a 10(1) \\
\hline
\end{tabular}

Fuente: elaboración propia, 2011.

\section{Variable 4.1: Actores involucrados}

Indicador 4.1.a: Actores sociales involucrados en el programa o proyecto

En este caso, la escala para el intervalo de 5 a 10 corresponde a la recta de distribución siguiente, teniendo en cuenta que al menos 3 ítems se han seleccionado para pertenecer a esta categoría:

Si hay en total 1 ítem seleccionado (x1), el valor correspondiente es 5 (yl).

Si hay en total 17 ítems seleccionados (x2), el valor correspondiente es 10 (y2).

Los valores intermedios responden a la ecuación de la recta siguiente:
Valoración $(y)=5 / 14\left(\mathrm{~N}^{\circ}\right.$ de ítems seleccionados (x) -3$)+5$

Método de ponderación: Matriz de asignación por atributos, de escala combinada (escala discreta (1) y escala de regresión lineal en intervalo de 5 a 10).

\section{VARIABLE 4.2: Espacios de ARTICULACIÓN}

Indicador 4.2.a: Tipo de articulación entre los actores sociales

Para este caso, el método de ponderación es el siguiente:

Matriz de asignación por atributos, de escala discreta $(1,7$ y 10$)$. 
Indicadores 4.2.b y 4.2.c:

Espacios de involucramiento y asociación generados / capitalizados / reforzados y grado de institucionalización del/los espacios de involucramiento y articulación actoral

Indicador 4.4.d: Participación de las familias beneficiarias en las diferentes etapas del programa o proyecto

Para estos indicadores, la escala del intervalo de 5 a 10 corresponde a la recta de distribución siguiente:

Si hay en total 1 ítem seleccionado del grupo (x1), el valor correspondiente es 5 (yl).

Si hay en total 6 ítems seleccionados del grupo (x2), el valor correspondiente es 10 (y2).

Los valores intermedios responden a la ecuación de la recta siguiente:

Valoración $(\mathrm{y})=\mathrm{N}^{\circ}$ de ítems seleccionados $(\mathrm{x})+4$.

Método de ponderación: Matriz de asignación por atributos, de escala combinada (escala discreta (1) y escala de regresión lineal en intervalo 5 a 10).

\section{Conclusión}

Este trabajo persigue como objetivos la identificación, caracterización y justificación de indicadores interrelacionados de gestión socio-habitacional que, apoyado en una visión integral y multiactoral, permitieran ponderar el grado de implementación local de procesos integrales y asociativos de hábitat social destinados a los sectores de menores recursos. Para ello, no solo se caracterizó la situación socio-habitacional regional como marco contextual de la investigación, sino que, además, se definió el rol que le compete a los gobiernos locales de ciudades no metropolitanas frente a las nuevas tendencias y desafíos planteados.

Se proponía favorecer la consolidación, optimización y/o modificación gradual de los modelos de gestión vigentes, a fin de contribuir con el mejoramiento de la capacidad municipal frente al problema socio-habitacional que padecen. Toda estrategia de modificación de los criterios y modos de actuación de un determinado actor social frente a una determinada problemática, presenta diferentes fisonomías según el lugar o base operativa desde donde se proponga realizar el cambio.

De esta manera y concibiendo al gobierno local como actor protagónico en esta tarea, el estimular el paso de un modelo de gestión tradicional como el predominante, hacia uno de gestión integral y multiactoral superador en términos sociohabitacionales, supone capitalizar las incipientes incorporaciones que se detectan en algunos casos modélicos, y significa para los propios municipios impulsar no solo una actividad técnica, sino un proceso político. Proceso en el que los conflictos o trabas existentes no son obstáculos infranqueables 
sino que a través de la acción dialogal, de la discusión y del debate, de la negociación y de la transacción, de los pactos y de las coaliciones, se introduce una cierta "gimnasia de articulación" dentro de los procesos de gestión tradicionales, garantizando la canalización positiva de dichos conflictos e intereses en la consecución de soluciones posibles y alternativas de lo socio-habitacional.

Desde este marco conceptual, ideológico y metodológico, se ha desarrollado este trabajo de investigación, y el sistema de indicadores propuesto resulta un instrumento útil y adecuado para la gestión socio-habitacional. Permite, con alto nivel de adecuación y certeza, desde una visión integral y multiactoral, ponderar el grado de implementación local de procesos integrales y asociativos de hábitat social destinados a los sectores de menores recursos, a diferentes niveles y escalas de análisis.

A través de dicho sistema, la gestión del hábitat hace explícita referencia a la consideración de la vivienda como proceso social y a lo local, es decir, al territorio y al contexto (físico, social e institucional) donde se consuma el hecho, como factores claves. Por otra parte, considera de lleno la permanente dicotomía entre política y técnica en la gestión pública. Se superan así enfoques meramente físicos y se postula la consideración de variables usualmente excluidas o marginadas en estudios habitacionales, como las conceptuales, las políticas y las institucionales, las cuales poseen alto valor de condicionamiento e incidencia en los escenarios existentes y resultados alcanzados.

Estos factores resultan determinantes a la hora de pensar estrategias superadoras de las vigentes, ya que los procesos socio-espaciales relacionados con el acceso a la ciudad y las formas de producción del hábitat -particularmente las de los sectores de menores ingresos- son esencialmente locales.

De la misma manera, facilita la detección de pautas o puntos de entrada viables que ponen en evidencia la cotidiana oportunidad de encontrar las hendijas de flexibilización que las políticas vigentes y el modelo de gestión tradicional permiten, en pos de avanzar hacia modelos más eficaces de gestión socio-habitacional desde los ámbitos locales de escala intermedia, aunque extensibles a otros ámbitos geográficos de gobierno.

Los mismos constituyen una estrategia a analizar y fortalecer, como potencial vía de reconversión paulatina de los paradigmas que rigen las vigentes políticas sociales (entre ellas la habitacional) en el actual contexto, ya que el desarrollo sociohabitacional local no es algo exógeno al territorio, donde políticas de gobiernos centrales e influjos externos resultan determinantes sino que, bajo parámetros integrales y participativos, es posible que sea generado y construido a partir de capacidades relacionales de los diferentes actores personales e institucionales, desde una proximidad no solo 
geográfica, sino fundamentalmente ideológica, organizativa e institucional.

También se resalta el énfasis que los procesos poseen sobre los productos, ya que los tipos de productos a nivel socio-habitacional no constituyen condicionantes claves del tipo de gestión e impactos generados, sino las modalidades en que éstos se ejecutan y desarrollan.

Esto refuerza aún más la hipótesis sostenida en el mismo sentido, al afirmar que "el territorio es un sujeto y el desarrollo (socio-habitacional) un proceso de construcción política. Lo local representa su punto de encuentro, el ámbito donde los agentes territoriales adquieren capacidad de fijar el rumbo, de 'construir' desarrollo. Es, por tanto, un proceso territorializado de maduración social (aprendizaje colectivo para el cambio cultural) y construcción política que se despliega en múltiples dimensiones"38.

De esta forma, los ámbitos locales y la vivienda concebida integralmente constituyen claras oportunidades para la innovación política; para experimentar nuevos abordajes, nuevas formas de participación y nuevas relaciones entre el estado y los ciudadanos. Y resultan espacios favorables para provocar e institucionalizar cambios en los modelos de gestión de las políticas sociales vigentes.

38 Ibíd.

106 revista invi № 77 / Mayo 2013 / Volumen № 28: 69-109
Fortalecerlos conceptual e instrumentalmente resulta una tarea y un desafío inminente. Tarea en la que este trabajo ha intentado contribuir con sus aportes.

\section{Bibliografía}

AGUILAR VILLANUEVA, Luis F. Gobernanza y gestión pública. México, Fondo de Cultura Económica. 2006. 500 p. ISBN 978-968-16-8133-3.

ARNOLETTO, Eduardo, et al. Índice de desarrollo local para la gestión. Córdoba, Argentina, EDUCC Editorial de la Universidad Católica de Córdoba. 2004. 210 p. ISBN: 987-21219-5-8. Colección PROFIM.

CORTÉS ALCALÁ, Luis. La vivienda como objeto de comprensión. En: CORTÉS ALCALÁ, Luis, comp. Pensar la vivienda. Madrid, España, Talasa Ediciones. 1995. 182 p. ISBN 84-88119-35-6. Colección Agora.

GARGANTINI, Daniela. Gestión local del hábitat: experiencias en municipios intermedios. Córdoba, Argentina, EDUCC Editorial de la Universidad Católica de Córdoba. 2005. 277 p. ISBN 987120339X, 9789871203390. Colección Thesys 7.

GARGANTINI, Daniela. Índice de gestión socio-habitacional en gobiernos locales intermedios. 
Argentina, Universidad Nacional de Rosario. 2010. Tesis doctoral en Arquitectura. Mimeo no publicado.

GARGANTINI, Daniela. Modelos de gestión de políticas socio-habitacionales en gobiernos locales. En: GARGANTINI, Daniela. Gestión local del hábitat: experiencias en municipios intermedios. Córdoba, Argentina, EDUCC Editorial de la Universidad Católica de Córdoba. 2005. 277 p. ISBN 987120339X, 9789871203390. Colección Thesys 7.

GARCÍA DELGADO, Daniel, comp. Hacia un nuevo modelo de gestión local: municipio y sociedad civil en Argentina. Argentina, Oficina de Publicaciones del CBC, Universidad de Buenos Aires. 1997. $373 \mathrm{p}$.

GÓMEZ, Julio Alguacil. Veinticinco tesis sobre la complejidad del concepto de lo social en las intervenciones de vivienda pública. En: CORTÉS ALCALÁ, Luis, comp. Pensar la vivienda. Madrid, España, Talasa Ediciones. 1995. 182 p. ISBN 8488119-35-6. Colección Agora.

GROOTAERT, Christiaan et al. Measuring social capital. An integrated questionnaire. Washington D.C, Estados Unidos, World Bank. 2004. 53 p. ISBN 0-8213-5661-5. Working Paper Nº18.

HERZER, Hilda. El rol de los actores en la construcción y la gestión de la ciudad. En: MAESTRÍA en Hábitat y Vivienda - Facultad de Arquitectura, Urbanismo y Diseño. Mar del Plata, Argentina, Universidad Nacional de Mar del Plata. 1999. 128 p. Módulo 4.
HERZER, Hilda y PÍREZ, Pedro. La gestión urbana en ciudades intermedias de América Latina. En: MAESTRÍA en Hábitat y Vivienda - Facultad de Arquitectura, Urbanismo y Diseño. Mar del Plata, Argentina, Universidad Nacional de Mar del Plata. 1999. 128 p. Módulo 4.

INDEC. Propuesta de Indicadores Municipales para la Gestión. Programa de Información Estadística y Apoyo a los Municipios (PRINEM). Buenos Aires, Argentina, INDEC. 1998

MAC DONALD, Joan. Pobreza y precariedad del hábitat en ciudades de América Latina y el Caribe. Santiago de Chile, CEPAL. 2004. 190 p. ISBN 9-1322606-3. Serie Manuales 38.

MAX NEEF, Manfred; ELIZALDE, Antonio y HOPENHAYN, Martín. Desarrollo a escala humana: una opción para el futuro. Santiago, CEPAUR. 1986. $100 \mathrm{p}$.

NACIONES Unidas. Panorama social de América Latina 2006. [En línea]. Santiago, Chile, CEPAL, Naciones Unidas. 2007. 426 p. ISBN 978-921-322972-9. Disponible en: http://www.eclac. $\mathrm{cl} /$ cgi-bin/getProd.asp?xml=/publicaciones/ $\mathrm{xml/0/27480/P27480.xml \& xsl=/dds/tpl/p9f.}$ xsl\&base=/tpl/top-bottom.xslt.

NACIONES Unidas. Panorama social de América Latina 2004. [En línea]. Santiago, Chile, CEPAL, Naciones Unidas. 2005. 391 p. ISBN 921322621 7. Disponible en: http://www.eclac.cl/cgi-bin/ getProd.asp?xml=/publicaciones/xml/6/20386/ P20386.xml\&xsl=/dds/tpl/p9f.xsl\&base=/tpl/ top-bottom.xslt

revista invi № 77 / Mayo 2013 / Volumen N² 28: 69-109 107 
NACIONES Unidas. Panorama social de América Latina 2011. [En línea]. Santiago, Chile, CEPAL, Naciones Unidas. 2012. 250 p. ISBN 978-92-1221087-2. Disponible en: http://www.eclac.cl/ publicaciones/xml/1/45171/PSE2011-PanoramaSocial-de-America-Latina.pdf

OSZLAK, Oscar y O`DONELL, Guillermo. Estado y políticas estatales en América Latina: hacia una estrategia de investigación. Redes Revista del Centro de Estudios e Investigaciones de la Universidad Nacional de Quilmes. 2(4): 99-128, septiembre 1995. 214 p. ISSN 0328-3186.

OSZLAK, Oscar y ORELLANA, Edgardo. El análisis de la capacidad institucional: aplicación de la metodología SADCI. [En línea]. Oscar Oszlak. 1993. Artículo inédito. [Fecha de consulta: diciembre de 2000]. Disponible en: http://www.oscaroszlak. org.ar/images/articulos-espanol/OSZLAK\%20 Oscar $\% 20$ y 20ORELLANA\%20Edgardo\%20 $\% 20$ El\%20analisis $\% 20$ de $\% 201$ a $\% 20$ capacidad\%20institucional.pdf.

PELLI, Víctor. Gestión de la vivienda II - Formas participativas de la gestión habitacional. En: MAESTRÍA en Hábitat y Vivienda. Facultad de Arquitectura, Urbanismo y Diseño. Mar del Plata, Argentina, Universidad Nacional de Mar del Plata. 2000. 100 p. Módulo 12.

PELLI, Víctor. Del campo a la ciudad. La comunidad que surgió de una emergencia. En: SALAS, Julián, coord. Viviendo y construyendo. Santa Fe de Bogotá, Colombia, Escala. 1994. p. 144-150. ISBN 958-9082-83-1.

108 revista invi № 77 / Mayo 2013 / Volumen № 28: 69-109
PÍREZ, Pedro. Indicadores municipales en la Argentina. Una propuesta y condiciones de realización. En: PRIMERA Jornada de Trabajo SINAIM (noviembre de 2000. Buenos Aires, Argentina).

RAMÍREZ, Ronaldo. Evaluación social de políticas y programas de vivienda: un análisis de la contribución de la vivienda a la reducción de la pobreza urbana. [En línea]. Boletín del Instituto de la Vivienda. 17(45): 9-57, mayo 2002. ISSN 0716-5668. Disponible en: http://www.revistainvi.uchile.cl/ index.php/INVI/article/view/380/823.

UN-HABITAT. The Recife declaration. Urban poverty: a world challenge. [En línea]. UN-HABITAT: International Forum on Urban Poverty (IFUP). Marzo 1996. Disponible en: http://ww2.unhabitat.org/ programmes/ifup/rde.asp.

RED RSU - Asociación de Universidades Jesuitas de Latinoamérica - AUSJAL. Política y sistema de autoevaluación y gestión de la responsabilidad social universitaria en AUSJAL. Córdoba, Argentina, Alejandría Editorial. 2009. 94 p. ISBN 978-987-24861-9-8

RODRÍGUEZ, Marcela, et al. Indicadores de impacto de proyectos participativos de hábitat popular. Córdoba, Argentina, SEHAS, SERVIPROH, CONICET, Universidad Nacional de Córdoba y MISEREOR. 2001. 175 p.

ROMERO, Gustavo, coord. y MESíAS GONZÁLEZ, Rosendo, coord. Participación en el planeamiento y diseño del hábitat popular. La Habana, CYTED Red XIV.B Programa. 1999. 231 p. 
SANÍN ÁNGEL, Héctor. Control de gestión y evaluación de resultados en la gerencia pública (metaevaluación-mesoevaluación). [En línea] Santiago, Chile, Instituto Latinoamericano y del Caribe de Planificación Económica y Social ILPES, CEPAL, Naciones Unidas. 1999. 104 p. ISBN 92-1-3215142. Serie Manuales 3. Disponible en: http://www. eclac.cl/cgi-bin/getProd.asp?xml=/publicaciones/ xml/4/6964/P6964.xml\&xsl=/ilpes/tpl/p9f.xsl.

SUBSECRETARÍA de Asuntos Municipales. Sistema básico de indicadores municipales (SIBIM) prueba piloto [En línea]. Instituto Nacional de Estadística y Censos. 2000. [Fecha de consulta: junio 2009]. Disponible en: http://www.indec.gov.ar/ proyectos/prinem/publicacion/sibiml.htm.

TOBELEM, Alain. Institutional capacity analysis and development system (ICADS). World Bank. 1992. 92 p. Occasional Papers Series No 9.

UNITED NATIONS. World urbanization prospects. The 2001 revision. Data tables and highlights. Nueva York, USA. [En línea]. United Nations. 2002. [Fecha de consulta: junio 2009]. Disponible en: http://www.un.org/esa/population/publications/ wup2001/wup2001dh.pdf. 